\title{
Research on Facilitating Function of Benevolence in Green Manufacturing —— Teachings from Tao Te Ching and Hua Hu Ching
}

\author{
Yingjie Guo $^{1, \mathrm{a}}$ \\ ${ }^{1}$ School of Foreign Languages Shaanxi Normal University, \\ Xi'an 710062, China \\ aguoyingjie@snnu.edu.cn
}

\begin{abstract}
To describe the reason why benevolence is a facilitator in Green Manufacturing, the paper refers to Tao Te Ching and Hua Hu Ching and examines the role as well as the value of benevolence in Green Manufacturing, holding that benevolence implies a philosophical attitude and reveals a humanistic belief. Besides, benevolence functions as a foundation of the establishment of Green Manufacturing, it serves as a stimulating factor of the development of Green Manufacturing, it acts as a consolidating facet of the maturity of Green Manufacturing and it promises a harmonious future of Green Manufacturing. Finally, in terms of the suggestions to maintain the proper fulfillment of benevolence in Green Manufacturing, the paper declares that keeping a persistent spirit, having a universal mind and maintaining an alert insight are fundamentally significant in the practice of Green Manufacturing.
\end{abstract}

Keywords: Green Manufacturing, Benevolence, Facilitator, Tao Te Ching, Ниа Ни Ching.

\section{Introduction}

It is universally acknowledged that Green Manufacturing has been serving as a fairly valuable and potential force in stimulating the stable development of our national economy[1]. On the one hand, Green Manufacturing attempts to rescue the limited resources from the edge of being rudely destroyed by man, and on the other hand, it tends to renew and then revive the unbalanced relationship between man and man, man and nature, man and society as well as nature and society. Essentially, Green Manufacturing exists and initiates from the very consideration of man (or man's interest) and nature (or nature's being). Tao Te Ching reveals that "Man followeth the formula of Earth; Earth followeth that of Heaven, and Heaven that of the Tao. The Formula of the Tao is its own Nature."[2] "Man", "Earth", "Heaven" and "Tao" are independent, but at the same time, they are integrated and influence each other. From this perspective, to guarantee a harmonious relationship between man and the world or man and nature requires a comprehensive examination of not only Green Manufacturing science and technology but also our human conscience and responsibility, among which benevolence is one of the crucial factors that work effectively for manufacturing engineering and ourselves. Admittedly, benevolence is such a significant and recognized quality of human life that it has been considered as a virtually stimulating medium to enhance the formation of our harmonious society. And as a representative element of the society, benevolence weighs much in Green Manufacturing. However, what role does it play in Green Manufacturing? What value makes benevolence so unusual in the development of the green manufacturing technology? With these questions, we intend to sort them out and hope to do some good to our scientific studies about Green Manufacturing today.

\section{Role of Benevolence in Green Manufacturing}

\subsection{Benevolence Implies a Philosophical Attitude}

Hиа Ни Ching says that "Men and women who wish to be aware of the whole truth should adopt the practices of the Integral Way" and "Acceptance is the very essence of the Tao"[3]. The descriptions here can be cited as the traces of the philosophical influence of benevolence upon Green Manufacturing. Benevolence, according to Random House Webster's College Dictionary, relates to the "desire to do good to others" and "cares for the well-being of all things", and it is basically a sort of "goodwill" or a "charity". Correspondingly, it is represented as "an act of kindness" or in a form of "charitable gift"[4]. Initially, benevolence concerns the objective aspect of Green Manufacturing. Green Manufacturing appears for the sake of mankind and works for the benefits of the real world. Acceptably, Green Manufacturing is a modern manufacturing mode that integrates the importance of environment and the consumption of resources[1,5]. Additionally, benevolence concerns the communicative aspect of Green Manufacturing. In the cycling process of various products regarding their designation, production, package, transportation, application, etc., Green Manufacturing strives for the minimum disadvantaged effects upon environment and the maximum utilization of resources which aims to harmonize and optimize the economic 
efficiency and social benefits in man's world[5]. Thirdly, benevolence concerns the revelatory aspect of Green Manufacturing. From Green Manufacturing's alternative names, i.e., Environmentally Conscious Manufacturing(ECM) and Manufacturing For Environment(MFE), we can observe one basic pattern of its intentions. Green Manufacturing highlights "green" in virtue of its own nature and emphasizes its destination through reducing the possible waste of resources and the worsening influence upon human living conditions. The whole course philosophically associates life, humanity, love, responsibility and even commitment so as to make people "live in accord with it, share with others the teachings that lead to it'[3] and enjoy the accomplished undertakings in a universal sense.

\subsection{Benevolence Reveals a Humanistic Belief}

Benevolence, like "respect, forgiveness, trustworthiness, diligence, and generosity", is an indispensable part of human virtues admired by man, fulfilled for man and put into effect to man[6]. Firstly, the settlement of the environmental and resource problems needs the participation of man's benevolence. And these unsolved problems are still one of the major concerns that mankind is confronted with in the long period of our time. In the course of man's production, the deterioration of environment, resulted from man's improper treatment, brings great anxieties and even dangers to the existence and development of our society. Furthermore, our research and study prove repeatedly that man's unreasonable way of approaching nature and natural resources has caused uneasy and severe consequences around us and the environmental problems are not basically alone from other social issues. Instead, they are closely connected and intervened. Sometimes, the environmental problems will lead to unexpected disastrous happenings that we cannot afford in the long run. As we can observe, "If your willingness to give blessings is limited, so also is your ability to receive them"[3]. Hence, the well-balanced management between benevolence and Green Manufacturing not only concerns how we take the advantage of our social and environmental resources, but also regards the reproduction and reuse of the resources all around us. If so, Green Manufacturing will benefit the harmonious "beings" of nature and man at the same time "in keeping with the Way"[3].

\section{Value of Benevolence in Green Manufacturing}

\subsection{Benevolence Functions as a Foundation of the Establishment of Green Manufacturing}

To some degree, it is a very fact that without benevolence, without the establishment of Green Manufacturing. "Know it as it was known in the beginning"[2], as Tao Te Ching puts it. Benevolence concerns the happiness of life and has an inclination to do good to people, society and the world, aiming to bring charity and benefits to man and our environment. Virtually, when the issues about the preliminary studies of Green Manufacturing happened in 1980s and the real systematic establishment of Green Manufacturing characterized itself in 1996 with Green Manufacturing by American Society of Manufacturing Engineers[7], Green Manufacturing was inevitably and accordingly founded on the basis that manufacturing should care more about man and man's life "by adopting the practices of the Integral Way"[3]. On the one hand, while man constantly demands from nature, man also unconsciously does harm to nature and even damages it in and out, making man completely embarrassed and shamed at times; on the other hand, the draining of the natural resources and the contamination of the tender environment have brought about untold troubles and headaches to man, which transparently begin to threaten man's life and society. The word "Green" in "Green Manufacturing" is hence a warning as well as a hope that calls on people to consider and reconsider what they have undertaken and what they are going to undertake. "Green" relates to life and it also relates to the practice of benevolence that functions as a foundation "through the linking of individual minds with the universal minds"[3].

\subsection{Benevolence Serves as a Stimulating Factor of the Development of Green Manufacturing}

Green Manufacturing needs fine and flexible environment to develop for its designed destinations. However, development does not mean waiting in vain or obtain providence from God faintly. It requires stimulating factors to help its course advance smoothly. One of the factors to stimulate the development of Green Manufacturing is benevolence, which turns up especially when men drift away "from the way of the Tao"[2]. Generally, benevolence not only maintains the capabilities of integrating man's well-composed qualities and cohesive force but also serves as a power to realize the ambition of "sustainable development" for the long-cherished dreams of human beings[5]. Benevolence allows man to take time to coherently think about the details of how to make full use of our limited resources and benefit the development of Green Manufacturing on its own. Benevolence implies that manufacturing should change and revolutionize the conventional mode of merely catering for profits and costs, instead, it should observe the actual conditions of environment and resources, meet the new demands of the new age and follow the new requirement of our society to develop itself[8]. In short, benevolence involves manufacturing engineers' careful evaluation of the importance of environment and resources and makes them practice the ideals of Green Manufacturing voluntarily.

\subsection{Benevolence Acts as a Consolidating Facet of the Maturity of Green Manufacturing}

Green Manufacturing longs for a mature state of its own because it eventually has to examine the truth and worth of itself and intends to prove its being valuable and 
unquestionable. To put the course in a "golden mean"[6], Green Manufacturing has to employ benevolence to participate as planned. To start with, benevolence may help Green Manufacturing focus on the complete process of making products and the overall cycling management of the products, not merely on the final emission stage to manage the obviously discharged pollutants, but also on the control and prevention of the origins of pollutions in the process of planning, manufacturing and molding of products, which includes the work of market survey, product design, technological innovation, quality analysis, assembling, sales and after-sale services, waste monitoring, recycling of the discarded, etc.[1,7]. In this course, "The soft conquereth the hard; the weak pulleth down the strong"[2]. Besides, benevolence may help manufacturing engineers willingly take the advantage of their abilities, wisdom and skills in the practice of Green Manufacturing and let them feel fulfilled about their own jobs, thus making manufacturing "Green" in a real sense, just as Lao Tzu remarks, "True realization comes from the direct merger of one's being with the divine energy of the Tao." [3]

\subsection{Benevolence Promises a Harmonious Future of Green Manufacturing}

Green Manufacturing is one of the prominent features of our society that characterizes itself with harmony[6]. If it works well, benevolence will prepare the possibility of retaining the soul of sustainable development for Green Manufacturing in the future. Apart from the truth that manufacturing can improve the efficiency of resource utilization to capacity so as to eliminate the waste of resources and lessen the level of polluting environment, Green manufacturing may avoid certain social disputes with the help of benevolence. In this case, Green Manufacturing takes the responsibility of bettering the environment of the working staff, perfecting their living conditions and ensuring their security, which may make them believe that a bright future is before them and they have the duty to put their potentials into practice to increase their work efficiency[8]. In addition, benevolence is also available for Green Manufacturing to shape a preferable enterprise image. It is fairly valuable because benevolence may bring intangible assets for enterprises through the minute undertakings of Green Manufacturing. And at the same time, it will, to an unusual extent, protect and ameliorate the deteriorating environment we are confronted with. Last but not least, we need to refer to the charm of benevolence and make it act on manufacturing rather than passively obey the orders from the government or dumbly follow the items of the law. We should actually regard benevolence as part of our ethical spirit that can "calm the mind and bring one into harmony with all things"[3] while considering Green Manufacturing as the strategic channel to have foothold.

\section{Suggestions to Maintain the Proper Fulfillment of Benevolence in Green Manufacturing}

\subsection{We Should Keep a Persistent Spirit}

Honestly, "Not all spiritual paths lead to the Harmonious Oneness"[3], so benevolence is not almighty as well, particularly when benevolence happens to "meet" Green Manufacturing. Green Manufacturing is a systematic engineering career, which needs the cooperation of both social endeavor and economic participation. On the one hand, Green Manufacturing is still developing though it has existed for years. In the course of its fulfillment, there must be kinds of unexpected difficulties and unidentified hard situations so we can not lose heart or become hopeless. Instead, we had better know that "difficulties are the very road to immortality"[3]. On the other hand, we can not feel proud of ourselves when we have achievements because "Pride always goes before a fall". We should keep a persistent spirit no matter how sticky the difficulties would be and no matter how marvelous the achievements we have made. We should enquire our inner soul because benevolence lets us maintain a unique style, a style of our own. Thus, it is wise to "regard these teachings with reverence, practice their truths, (and) illuminate them to others"[3].

\subsection{We Should Have a Universal Mind}

Green Manufacturing has its particular Tao[2]. We cannot alternatively make adjustments to our heart's content though we may arrange certain manufacturing procedures in the name of benevolence. The truth is that our heart should be "the universal heart" and our mind should be "the universal mind"[3]. Any practice has its own rule or law, so does Green Manufacturing. We ought to have a universal mind in this aspect because Green Manufacturing has to carry on step by step and follow its own way according to its nature or style. By referring to benevolence, we cannot break or destroy the natural rule and ignore the importance of "the universal law" as Green Manufacturing still goes on. Maybe we should bear in mind that "The highest virtue one can exercise is to accept the responsibility of discovering and transmitting the whole truth"[3]. In this sense, we may realize that violating the rule or law of Green Manufacturing equals violating the basic living rights of our human beings. And obviously, having a definite object in life and integrating benevolence into manufacturing are objectively demanded.

\subsection{We Should Maintain an Alert Insight}

"Standing still" is doomed to fail because all social machines are moving ahead. Confining ourselves merely in a small world is also improper as we need the multidisciplinary studies to help Green Manufacturing grow. As for benevolence, it should be a flexible strategy instead of a cold slogan. To guarantee the peaceful operation of Green Manufacturing in the long run, we should maintain an alert insight about its "now" and "future". Since we have the 
careful observation of our "past", we should know our lessons and at the same time make sure that we will not copy the past "stupidity" right "now" or in the "future" any longer otherwise we will lose more consciously or unconsciously. For one thing, we had better create a characteristic style of Green Manufacturing for ourselves because we have distinctive actual situations and particular working backgrounds. We should make good use of benevolence and let it function well by considering the realities "now". For another, "know your enemy and know yourself, victory will not be at risk; know both heaven and earth, and victory will be complete"[9], so we also have to learn good lessons and obtain abundant references from the developed countries like America, Russia, Japan, Britain, France, etc., because it is essential to know what level these countries have reached or achieved in the aspect. No contrast, no difference. And it is true that working behind closed doors will be dangerous and unpromising so we should maintain an alert insight to acquire the advantages of different disciplines, learn from developed countries and know well about the latest international trends of the development of Green Manufacturing.

\section{CONCLUSIONS}

Green Manufacturing is an indispensable part of the world development. Especially in the air of the world globalization, Green Manufacturing occupies a particular position and plays a significant role in human life. Yet Green Manufacturing cannot live without benevolence, as we can observe from its essence. Most important of all, benevolence displays itself as a facilitator in Green Manufacturing. By observing the role of benevolence in Green Manufacturing, we may find that benevolence is a philosophical attitude as well as a humanistic belief. By considering the value of benevolence in Green Manufacturing, we may know that benevolence functions as a foundation of the establishment of Green Manufacturing, it serves as a stimulating factor of the development of Green Manufacturing, it acts as a consolidating facet of the maturity of Green Manufacturing and it promises a harmonious future of Green Manufacturing. In terms of the suggestions to maintain the proper fulfillment of benevolence in Green Manufacturing, we should keep a persistent spirit, have a universal mind and maintain an alert insight, and all the jobs seem meaningful.

\section{Acknowledgments}

The research described in this paper is financially supported by Shaanxi Social Science Fund(2014J11), the Innovation Funds of Graduate Programs (2013CXB013), Shaanxi Social Science Association (2013Z092); the research programs sponsored by SNNU Elementary Education Curriculum Research Center of Ministry of Education of China (JCJY201318), SNNU; 2013 Visiting Scholar Exchange Program (P-1-04989), SNNU; Shaanxi
Social Science Fund (08K005); and Ministry of Education of China (GPA105004, 10YJA752031).

\section{References}

[1] S. M. Ao, "Green Manufacturing-a sustainable and modern developing mode," Journal of Nanjing University of Technology, vol. 27, no. 4, pp. 106-109, July 2005.

[2] A. Crowley, Lao-tzu Tao Te Ching, York Beach: Samuel Weiser, Inc., 1995, pp. 40, 29, 33, 51.

[3] B. Walker, Hua Hu Ching, New York: Harper Collins Publishers, 1992, pp. 4-6, 42-43, 11-15, 65-66, 73, 91, 29, 19.

[4] Random House Webster's College Dictionary, New York: Random House, 1999, p. 124.

[5] F. Liu, H. J. Cao, and N. J. He, "On the research and tendency of green manufacturing," China Mechanical Engineering, vol. 11, no. 1-2, pp. 105-109, February 2000.

[6] D.W. Ma, Confucius Said, Shanghai: Shanghai World Book Press, 2004, pp. 64-65.

[7] S. A. Melngk and R. T. Smith, Green Manufacturing, Dearborn: Society of Manufacturing Engineers, 1996, pp. 2-5.

[8] D. M. Zhang and Y. Y. Wu, "Green manufacturing philosophy and effect for manufacturing enterprise," Machine Building \& Automation, vol. 5, pp. 4-6, April 2002.

[9] W.S. Lin, Sun Zi: The Art of War, Beijing: Foreign Languages Press, 2004, pp. 95-96. 